The University of Maine

DigitalCommons@UMaine

Publications

Senator George J. Mitchell Center for Sustainability

Solutions

6-2016

\title{
Sustainability Science Graduate Students as Boundary Spanners
}

Soencer Meyer

Vanessa Levesque

Karen H. Bieluch

Michelle Johnson

Bridie McGreavy

University of Maine, bridie.mcgreavy@maine.edu

See next page for additional authors

Follow this and additional works at: https://digitalcommons.library.umaine.edu/ mitchellcenter_pubs

Part of the University Extension Commons

\section{Repository Citation}

Meyer, Soencer; Levesque, Vanessa; Bieluch, Karen H.; Johnson, Michelle; McGreavy, Bridie; Dreyer, Stacia J.; and Smith, Hollie, "Sustainability Science Graduate Students as Boundary Spanners" (2016). Publications. 84.

https://digitalcommons.library.umaine.edu/mitchellcenter_pubs/84 
Authors

Soencer Meyer, Vanessa Levesque, Karen H. Bieluch, Michelle Johnson, Bridie McGreavy, Stacia J. Dreyer, and Hollie Smith

This article is available at DigitalCommons@UMaine: https://digitalcommons.library.umaine.edu/mitchellcenter_pubs/84 


\section{Sustainability Science Graduate Students as Boundary Spanners}

Current Author Details

(* Corresponding author)

Spencer R. Meyer, Ph.D.*

NatureNet Science Fellow

Yale School of Forestry and Environmental Studies

205 Prospect St.

New Haven, CT 06511-2106

United States of America

spencer.meyer@yale.edu; 207.852.3171

Vanessa R. Levesque, Ph.D.

School of Economics

University of Maine

Orono, ME

United States of America

Karen Hutchins Bieluch, I.Ph.D.

Practice-Based Learning Specialist

Environmental Studies Program

Dartmouth College

Hanover, NH

United State of America

Michelle L. Johnson, Ph.D.

Social-Ecological Scientist

U.S. Forest Service, New York City Urban Field Station

New York, NY

United States of America

Bridie McGreavy, Ph.D.

Assistant Professor of Environmental Communication

Department of Communication and Journalism

University of Maine

Orono, ME

United States of America

Stacia Dreyer, Ph.D.

Research Associate

School of Marine and Environmental Affairs

University of Washington

Seattle, Washington

United States of America

Hollie Smith, Ph.D.

Assistant Professor

Department of Communication Studies

Harrington School of Communication and Media

University of Rhode Island

Kingston, Rhode Island

United States of America 


\section{Acknowledgments}

This research was entirely funded by the Maine Sustainability Solutions Initiative (National Science Foundation Grant No. EPS-0904155). We thank Thomas Parr, for his encouragement to conduct this study. We thank our SSI colleagues Mark Anderson, Susan Gardner, and Linda Silka for thoughtful reviews of earlier versions of this manuscript. It was also greatly improved through comments by several anonymous reviewers. Finally, we are grateful for the mentoring and support of our faculty advisors and the SSI leadership. 


\begin{abstract}
Graduate training in sustainability science (SS) focuses on interdisciplinary research, stakeholderresearcher partnerships, and creating solutions from knowledge. But becoming a sustainability scientist also requires specialized training that addresses the complex boundaries implicit in sustainability science approaches to solving social-ecological system challenges. Using boundary spanning as a framework, we use a case study of the Sustainability Solutions Initiative (SSI) at the University of Maine to explicate key elements for graduate education training in SS. We used a mixed-methods approach, including a quantitative survey and autoethnographic reflection, to analyze our experiences as SSI doctoral students.
\end{abstract}

Through this research, we identified four essential SS boundaries that build on core sustainability competencies which need to be addressed in SS graduate programs, including: disciplines within academia, students and their advisors, researchers and stakeholders, and place-based and generalizable research. We identified key elements of training necessary to help students understand and navigate these boundaries using core competencies. We then offer six best-practice recommendations to provide a basis for a SS education framework. Our reflections are intended for academic leaders in SS who are training new scientists to solve complex sustainability challenges. Our experiences as a cohort of doctoral students with diverse academic and professional backgrounds provide a unique opportunity to reflect not only on the challenges of SS, but also on the specific needs of students and programs striving to provide solutions. 
Keywords: Sustainability, graduate education, interdisciplinary research, boundary spanning, organizational innovation, problem solving competencies 


\section{INTRODUCTION}

Today's global citizens live in a world rife with complex, or 'wicked' problems. Wicked problems are often characterized by competing value systems, unpredictable cause-effect relationships, high degrees of uncertainty, and multiple levels of government regulations (Rittel and Webber, 1973; Weber and Khademian, 2008). More than ever, scientists across disciplines are called upon to solve wicked problems, which tend to defy traditional, disciplinary, and institutional boundaries. These problems require faculty and students to gain competencies in collaboration and problem-solving that may not be developed during more traditional single-discipline training programs (Wiek et al., In Press).

Sustainability science (SS) has emerged as one answer to the question of how to address society's wicked problems (Clark, 2007; Kajikawa, 2008). Leaders in SS have advocated for a research agenda that increases the capacity to advance "actionable science" to serve society by informing, improving, or influencing decisions, policies, strategies, and behaviors that relate to the environment (Kates et al., 2001; Palmer, 2012). Recent research in SS is operationalizing what it means to develop sustainable solutions and link knowledge with action (Polk, 2014) by offering principles to guide the design and structure of sustainability projects (van Kerkhoff, 2014), and assessing progress made toward realizing the SS agenda (Miller et al. 2014). As SS matures as its own field, researchers are studying how academic institutions are training future scientists to identify and implement solutions (Barth et al., 2007).

Using a mixed-methods approach, including a quantitative survey and autoethnographic reflection, this study analyzes the experiences of one SS doctoral student cohort in order to contribute to the 
understanding of and offer suggestions for strengthening SS scientist training. Collectively as a cohort of doctoral students, we were actively engaged in and received training to solve wicked problems as part of our research experiences with Maine's Sustainability Solutions Initiative (SSI), which we describe in greater detail below. We worked on inter- and transdisciplinary teams with our faculty advisors, a range of cross-institutional partners, and outside stakeholders to conduct SS. Our projects included, for example: creating and evaluating alternative futures scenarios to support land use planning across scales; supporting the development of an innovative policy to regulate a vulnerable type of wetland habitat; and conducting sustainability needs assessments with municipal officials and state legislators to shape and communicate our research.

As we focused on specific projects with our faculty mentors and project teams, we also began to explore a broader question: What aspects of graduate education are necessary to prepare new researchers to successfully engage in SS? To begin, we reflected on and assessed our graduate training in a large SS initiative in the context of Wiek et al.'s (2011) framework of SS competencies to provide insights and recommendations for future students, faculty advisors, and leaders of SS research programs. Using the lens of "boundary spanning," we argue that although SS requires mastery in a broader suite of skills than traditional interdisciplinary studies, with the right institutional support, faculty participation, graduate student backgrounds, and a focus on teaching competencies, sustainability graduate programs can produce scientists fully capable of contributing solutions to wicked problems. Finally, we offer unique insights about the specific types of boundaries that occur in SS and how these boundaries shape the required SS training for students and faculty.

Building Blocks of Sustainability Science 
Sustainability has been defined in many ways, most commonly as meeting the needs of the current generation without compromising the ability of future generations to meet their needs (Bruntland Commission, 1987). Sustainability science distinguishes itself from other fields not only by focusing on the applied problem of understanding and promoting sustainability, but also by three specific dimensions through which SS is conducted (Clark and Dickson, 2003; Kates, 2011): (1) interdisciplinary research; (2) stakeholder-researcher partnerships; and (3) creating solutions from knowledge. At the core of SS, are the interactions between natural and social systems, or socialecological systems (SES). Complex problems that arise from SES typically lack a clear start or end (Kates et al., 2001) and solutions to those problems are not confined to an individual discipline. Interdisciplinary education demands a two-pronged approach: students must be knowledgeable in one discipline and they must "gain fluency in the ideas and language of various disciplines, and also the behaviors expected in various disciplinary communities" (italics added, Holley, 2009). SS further posits that to solve complex problems, relevant stakeholders must be engaged iteratively in the interdisciplinary research initiative from problem identification, through data collection, to problem solving. The term transdisciplinary is widely used in SS to refer to research-solutions processes that engage knowledge "from various scientific and societal bodies of knowledge" (Lang et al. 2012, p. 27). To be effective contributors to SS, students must be exposed to problem- and project-based learning (Brundiers and Wiek, 2013) to learn how to identify and manage researcher-stakeholder and interdisciplinary researcher-researcher relationships.

Furthermore, SS does not end with publication in a scientific journal, but must contribute to developing solutions for the target SES, such as through implementing policy, co-producing knowledge with stakeholders, developing technological fixes, or other means (Kajikawa, 2008). Therefore, SS is 
distinct from other interdisciplinary contexts in that it not only demands interdisciplinary approaches to understanding and solving problems, but also requires inter-organizational thinking focused on coupled systems and transitions management within SES (Kajikawa et al., 2014). Conducting science with solutions-oriented goals often demands a flexible, adaptive approach to research, which places dual pressures on scientists to contribute to one's field and contribute to the development of practical solutions. The need to train graduate students in the above three dimensions of SS is well-known, and researchers note that expertise in these areas is demonstrated through a combination of content knowledge and soft skills (Allen et al. 2014). The specific challenges students and faculty face in meeting the training needs are less well understood. Therefore, it is important for students to identify and then learn to manage typical boundaries encountered in SS and SS graduate student training.

Core Competencies in Sustainability Science

With prominent scientific organizations, such as the National Science Foundation (NSF), embracing SS, numerous major SS research and education programs have emerged at universities across the United States (Clark, 2007) (e.g. Arizona State University, Harvard University). If we consider newly trained $\mathrm{PhDs}$ as central to the advancement and promotion of SS, understanding and operationalizing their education pathways becomes particularly important (Wiek et al., In Press). Indeed, a growing body of research describes core competencies and pedagogical strategies for interand transdisciplinary collaboration in sustainability-related contexts (e.g. Barths et al., 2007; de Haan, 2006; Wiek et al., 2011). In particular, Wiek et al. (2011) provided a comprehensive framework of five individual-level competencies: systems thinking, interpersonal competence, anticipatory competence, normative competence, and strategic competence. They describe, for example, how strategic 
competence, or the ability to design, test, and implement solutions to complex problems, requires the ability to engage in systems thinking; anticipate futures; and identify and and negotiate values. Inter- or transdisciplinary solutions-oriented work requires skills that allow for the identification, negotiation, and transformation of the myriad boundaries that occur within SS (Reich and Reich, 2006; Wiek et al., 2011). Boundaries are an implicit dimension of core competencies in SS.

Boundary Spanning: Enhancing a Framework for Training

Although prior research on interdisciplinary graduate training (Borrego and Newswander, 2010; Graybill et al., 2006; Moslemi et al., 2009; Schmidt et al., 2012; Tress et al., 2009; Wagner et al., 2012) offers important insights relevant to education in SS, we argue that becoming sustainability scientists requires specialized training in how to cross the boundaries implicit in SS approaches to SS. As noted extensively in the SS literature (e.g. Miller 2014; van Kerkhoff, 2014; Polk 2014), SS requires refined academic training in inter- and transdisciplinary collaboration, including stakeholder engagement in solution-oriented research. Schmidt et al. (2012) used the boundary spanning concept to make recommendations for improving interdisciplinary and international graduate research training. Similarly, within SSI, the concept of boundaries and boundary spanning is used to frame the disconnect - particularly in environmental science — between the scientists conducting academic research and the policy-makers and citizens facing real-world challenges.

Integrated research requires scientists to critically question boundaries that favor scientific framing and problem analysis (Gieryn, 1983; Jasanoff, 1987) over non-expert or traditional ecological knowledge approaches. Sustainability science also requires researchers to cross institutional boundaries 
through partnerships with non-academic stakeholders, including policy makers and other groups to develop a "new contract" in which knowledge generation and problem-solving actions are inextricably linked (Bäckstrand, 2003; Polk 2014). The SS training literature lacks, however, the perspective of graduate students themselves, who often face these boundaries with little guidance on why or how to cross them. By studying our SS training through the lens of boundary spanning, this study offers new insights on graduate student education tailored to SS.

The boundary spanning metaphor is useful for understanding the typical distinctions and frequent barriers that occur between diverse types of institutions, expertise, audiences, and even geographic scales. Several theorists have developed strategies to build common languages and coordinate approaches to cross such boundaries, yet few of these approaches are cited as core to the training of sustainability scientists (Clark et al., 2011; Weerts and Sandmann, 2010). Whitmer et al. (2010) identified a critical need for academic training to, "provide mentoring, leadership training, networking, technical support, and innovative curriculum development to foster successful engagement" (p. 314). It is in this spirit that we use the boundary spanning framework to identify critical training areas that complement the Wiek et al. (2011) competencies. Specifically, we examined the formal and informal education that guides graduate students' ability to span four boundaries: (1) disciplines within academia; (2) students and their advisors; (3) academic researchers and stakeholder partners; and (4) place-based and generalizable research. In the remainder of this article we use these boundaries as the lens through which to reflect on our collective experience and to identify key learning opportunities that align with the aforementioned SS core competencies. 


\section{INTROSPECTION FROM A GRADUATE STUDENT COHORT}

Sustainability Solutions Initiative

The Sustainability Solutions Initiative (SSI) was a five-year, NSF funded, \$20 million research initiative at the University of Maine that sought to "connect knowledge with action in ways that promote strong economies, vibrant communities, and healthy ecosystems in and beyond Maine" (Hart et al., 2015). SSI used both place-based and stakeholder-driven research at local and regional scales to develop science-based solutions across three core research areas: (1) SES; (2) the linkage between knowledge and action; and (3) organizational innovation that supports SS. SSI utilized a portfolio approach characterized by multiple projects that cross-cut numerous disciplines, including ecology, natural resources, economics, education, communication, engineering, and others. In addition to several faculty and post-docs, SSI recruited and funded 28 doctoral students, each of whom was affiliated with one or more projects within the portfolio. This group of SS doctoral students, of which we were a part, has served as an incubator for innovation in graduate education and provides an opportunity to reflect on the specific aspects of training necessary to fledge the next generation of sustainability scientists.

\section{Our Approach}

We used a mixed-methods approach, including a quantitative survey and an autoethnographic reflection, to analyze our experiences as doctoral students in SS (Creswell, 2003). Researchers working in similar interdisciplinary contexts have demonstrated the value of an autoethnographic approach (Armstrong et al., 2012; Graybill et al., 2006). In this vein, seven of the 14 doctoral students who began 
their programs in 2010 (referred to as Cohort 1) gathered approximately once a month for a year starting in early 2012 to discuss and record individual and shared experiences. The four training boundaries discussed below were derived from a collaborative thematic analysis of meeting records from these gatherings.

To represent the entire SSI doctoral student population rather than only the members of Cohort 1 $(n=14)$, we supplemented our autoethnographic approach with a web-based Qualtrics survey, sent in January 2013 to all SSI doctoral students enrolled in the program at that time ( $\mathrm{n}=22)$, including members of Cohort 1. This group included first-, second-, third-, and fourth-year students. The survey included a combination of closed- and open-ended questions to elicit comparisons across individuals and specific contextual details of individuals. To achieve a consistent measure of disciplinarity, we used the definitions of multi-, trans-, and interdisciplinarity set forth by Miller et al. (2008). The survey also assessed the following: expectations of and motivations for joining SSI, the development of hard and soft skills relevant to researchers and professionals students' perceptions of the adequacy of their training as sustainability scientists, and basic background and demographic information. Master's students conducting SSI research were excluded from the survey because of the shorter duration of their programs and to focus this research on doctoral student training. Hereafter, we refer to the $\mathrm{PhD}$-level respondents simply as students. Of the 22 survey recipients, we received responses from 18 , including the seven authors of this manuscript, yielding a response rate of $86 \%$. Survey results deepened our understanding of, and in some instances challenged, the themes that emerged from our autoethnographic assessment.

Who we are 
SSI was administered as a research center rather than as an academic department; therefore, SSI students each have a home academic department, such as biology and ecology, communication and journalism, economics, forest resources, psychology, or wildlife ecology. There were no formal, unified curriculum requirements of SSI students, although a core SS readings course was offered each year. Survey results indicated that the most common $(n=7$, or $39 \%)$ degree sought was an Interdisciplinary $\mathrm{PhD}$, with another six (33\%) PhDs in Ecology and Environmental Science - an interdisciplinary degree granted from multiple academic departments. The remaining five $(28 \%)$ were $\mathrm{PhDs}$ in the subject of the home department, such as Forest Resources. Age is a distinguishing characteristic of SSI students. Results indicated they are older (the mode was the 31-35 category, and 5 respondents were over 35) than the national median age of 30 at which doctoral students in STEM disciplines graduate (National Science Foundation, 2012). Participants also reported having significant professional experience prior to enrolling in SSI. Five students had 5-10 years of experience, with four students having more than ten years of professional experience. Only two had less than one year of professional experience.

SSI student motivations for pursuing PhDs were diverse. A common theme discovered during informal discussions is that a high number of students were not interested in academic careers. There is evidence, however, that during the SSI program, some individual preferences for post-PhD career paths shifted towards academic paths (Dr. Susan Gardner, personal communication, February 13, 2013). Survey results indicated that $65 \%$ of SSI students were primarily interested in government, NGO, or private sector careers; $18 \%$ indicated interest in research and/or teaching at the university level, and $18 \%$ indicated they were equally interested in both. Furthermore, $53 \%$ reported an interest in pursuing 
research after their degree, regardless of institution type, indicating an affinity for conducting research, but not necessarily in a university setting.

Learning to Span the Boundaries

Using our autoethnographic reflections and survey results, we now focus on the four training boundaries that we assert sustainability scientists-in-training must learn to manage. We offer the following recommendations recognizing that SSI, like many SS programs, was itself an experiment: a high-risk, high reward program as NSF might describe it. All new programs go through trials and errors, and we hope our recommendations help other programs learn from our successes and shortcomings alike.

\section{Boundary 1: Disciplines within Academia}

Training graduate students in multiple disciplines is of growing interest (Evans and Randalls, 2008; Gardner et al., 2012; Schmidt et al., 2012). Sustainability science in particular aims to simultaneously and collaboratively address ecological, social, and economic system interactions and is necessarily more interdisciplinary than many other scientific fields (Schoolman et al., 2012). In contrast to interdisciplinary research that relies primarily on one discipline augmented by another (Miller et al., 2008), SS is unique in that it calls for truly integrating social, ecological, and economic disciplines in inter- and transdisciplinary ways. 
Our survey results demonstrate that graduate students often faced the paradox of being trained as interdisciplinary researchers from within existing disciplines. Many students stated that they wantedand were expected - to gain in-depth knowledge within their home discipline, but also to collaborate with other disciplines through the larger research teams to which they belonged. One student's statement exemplified these dual goals: "I expected to work with individuals from a variety of different disciplines, and gain a better understanding of alternative research methods and epistemologies." In addition to satisfying the requirements of their home departments, SSI students had just one SSI curriculum requirement: a one-credit SS readings course. Occasionally, relevant elective courses—such as conservation planning, university-stakeholder partnerships, and boundary spanning-were offered to bring together SSI students for coursework and to provide some interdisciplinary research training. However, these courses were neither required nor broadly taken by the full cohort of SSI students. Given the disparate departmental curriculum requirements, each SSI student, in collaboration with advisors, individually navigated the extent to which his or her research, and future career path, was discipline-specific or interdisciplinary. Of survey respondents, $71 \%$ classified their dissertation research as either inter- or transdisciplinary and only $12 \%$ stated their research was strictly disciplinary. All students held in common the challenge of negotiating the boundary between depth in one field and breadth across many fields, and shared an understanding of the importance of gaining both disciplinary and interdisciplinary theory and research skills.

In contrast to the lack of a common curriculum, SSI regularly provided informal interdisciplinary learning opportunities for graduate student training. There were numerous informal fora for discussions across disciplines, including "brown bag lunches" focused on SS problems and monthly SSI-wide meetings that included research updates from teams. In addition, there were ad hoc workshops, such as 
those offered on science communication and SES modeling. Although these formal and informal learning opportunities proved valuable to members of SSI, SSI students had varied opinions on whether these opportunities provided them with the dual training that they desired and expected. When asked whether they were getting the training needed to become sustainability scientists, only three (23\%) said they were. Of the remaining 10 respondents, $5(38 \%)$ indicated they were unsure and $5(38 \%)$ indicated they felt they needed more specialized SS training. Several students suggested that "core coursework in SS has been lacking." Others were satisfied with taking formal courses primarily in specific disciplines, but desired more informal training opportunities in interdisciplinary research:

I expected some focused discussions or workshops in how different types of data are brought together, how different ways of examining issues are combined, etc. I'm not sure if I thought that would happen at the [project] team level or at the whole SSI level, but regardless, it hasn't happened at all. I'm on my own to figure out how to do this.

Thus, while most students agreed that they were getting the discipline-specific training they needed from their home departments, there was a range of expectations about what type of training students should receive in interdisciplinary research, and a general lack of satisfaction in the degree of interdisciplinary training received. While we cannot comment on the degree of interdisciplinary training provided in other sustainability programs, we suggest sustainability focused graduate training programs should make a conscious effort to evaluate and define program expectations for interdisciplinarity.

These results suggest several opportunities for building on the strengths of the existing program and improving areas of weakness. For example, while there are downsides of having students scattered 
across university departments, the benefit is that most (but not all) students felt that they gained the deep knowledge in their individual disciplines required of doctoral students. This suggests that connecting SS graduate students with specific departments is a key aspect of their training. Our results also suggest, however, that SS programs must specifically provide interdisciplinary theory and research training. Placing students on interdisciplinary research teams and offering ad-hoc classes over a few years may not adequately prepare graduate students for careers in SS. Therefore, we recommend a short but required core curriculum (e.g. one course per semester for two years) that addresses the five key competencies of SS education: systems thinking, futures thinking, values thinking, strategic thinking, and collaboration. By gaining these key competencies, students will be better equipped to use interdisciplinary research and science communication to bridge theory and practice (McGreavy et al., 2013).

\section{Boundary 2: The Students and their Advisors}

Faculty advisors, whose mentoring style is often informed by their own graduate training experiences, are typically responsible for ensuring their doctoral students: (1) are appropriately trained in their subjects; (2) conduct valid and worthwhile research; and (3) are socialized in their disciplines (Weidman et al., 2001). While SS doctoral students require this disciplinary and institutional mentoring, they also require guidance on the other competencies of SS discussed above. Advisors may or may not be aware of the need to train students in these non-traditional skills. In addition, students themselves may come into a SS program with professional knowledge and experience related to solutions-driven research, stakeholder relationships, and interdisciplinary projects, altering the traditional faculty-student dynamic of mentor-mentee. In this situation, advisor and advisee are both 
able to benefit through mutual learning of SS competencies. Literature on interdisciplinary graduate education often points to the need for graduate advisors who are supportive of interdisciplinary research (Graybill et al., 2006; Schmidt et al., 2012; Tress et al., 2009), but does not explicitly address the gaps or the mutual learning that can come from training in non-traditional SS areas.

Our experiences shed light on the relationships between doctoral students and their advisors - a sometimes complicated boundary to manage - and suggest that mutual learning was acknowledged in only a fraction of student-advisor relationships. The strong support from many SSI advisors was clear in student responses: "My advisors embrace interdisciplinary research and have worked to make the interdisciplinary approach seamless in my comprehensive exam and dissertation processes." This support may be expected, since faculty advisors all applied for funding for students and to conduct projects under the umbrella of SSI. However, there was evidence that some students felt their advisors had less understanding and support for interdisciplinary research. For example, one student said: "My advisor has a fairly conventional and strict view of the role of depth in the doctoral program, bounded by fairly well-defined disciplinary boundaries and grounded in my field of specialization.” This suggests that not all faculty believe doctoral students should engage in inter- or transdisciplinary research during their training. Given the importance of having supportive faculty advisors for SS training programs, specific and deliberate effort must be made to ensure faculty advisors and students share a common understanding of graduate student research and training roles in SS programs. Without a common understanding, managing the student-advisor boundary becomes challenging as both parties attempt to direct the student's program. 
While many students reported advisor support for their interdisciplinary research, fewer reported having advisors able to provide guidance on how to conduct such research. Some students felt that SSI represented the first time their advisors engaged in interdisciplinarity, stakeholder research, or connecting knowledge with solutions. As is common in experimental programs, for many faculty, SSI was their first in-depth experience with this form of research. Interestingly, several SSI students reported bringing with them extensive experience in interdisciplinary work, either through previous academic training or professional work experience, thus, in some cases, reversing the traditional academic hierarchy of experience between advisors and students. Of the $88 \%$ of students who had previously earned master's degrees, $47 \%$ said their degrees were interdisciplinary. One student who had co-advisors from two different disciplines reported that "they brought me on to be the 'bridge' between their two disciplines."

The collegial mutual learning dynamic between advisors and students was not always present, however. Some students came to the program with specific SS skills that could contribute to the team, but did not feel empowered or equipped to use their skills on the team. It is unclear whether faculty members were given guidance or training on how to mentor students in non-traditional skills. For example, one student stated:

My research is pretty different from what [my advisor] does, so even though [my advisor] gets the big picture really well, and is excited about it, there is little guidance in terms of how to form research questions (or, even, what are appropriate research questions), how to develop methods, what types of journals to use as models, etc. 
In contrast, faculty who fostered a mutual learning relationship with their advisees fostered collegiality and respect between team members (McGreavy et al., 2015), with less of the intellectual hierarchy often present in advisor/advisee relationships. In response to these experiences, we recommend future SS programs should consider institutionalizing program expectations for SS mentoring and providing advisors with specialized training and materials which specifically address the SS interpersonal competency so they can understand and effectively facilitate mutual learning experiences among team members, including advisees. In addition, faculty advisors of SS graduate students should acknowledge early in the advisee relationship the extra challenges of SS and maintain open dialogue with their students about the skills each brings to the project. Finally, advisors and students should voice their respective expectations for mutual learning, interdisciplinary, and stakeholder-driven and solutions-based research.

\section{Boundary 3: Academic researchers and stakeholder partners}

Stakeholder-researcher partnerships are an integral aspect of SS. Numerous SS scholars argue that a collaborative approach to problem identification, research, analysis, and interpretation may be instrumental in connecting knowledge to action (Cash et al., 2003; Clark and Dickson, 2003; van Kerkhoff and Lebel, 2006; Whitmer et al., 2010). SSI fully embraced the significance of stakeholderresearcher partnerships at both institutional and team levels, and this aspect of sustainability was clearly communicated as important to both student and programmatic success. Forming and cultivating these partnerships is challenging and is not an implicit skill for doctoral students or faculty (Kueffer et al., 2012). For many, there is a significant knowledge gap in both the theory and practice of working with stakeholders. The former can be addressed with formal teaching, but the latter requires practice and experiential learning (Silka, 1999). Within SSI, such training was primarily experiential, augmented 
with a limited number of formal training opportunities, which by themselves often lacked direct applicability, or were optional. For example, an optional NSF-sponsored workshop on science communication was offered, which while important for general science communication, was not designed to focus on the complexities of partnerships themselves. In addition, an elective course on university-stakeholder partnerships was offered by a SSI faculty member who is a leading expert on partnership building. This course was not required for SSI students, and since it competed with student's attention to disciplinary and other course requirements, only a subset of SSI students were able to participate. With these few training exceptions, most of our experiences developing and leveraging university-stakeholder partnerships came from participation in our individual team research.

Individual teams approached stakeholder engagement in widely different ways and collaborated with different kinds of partners, including local citizens, state and federal regulatory agencies, industry partners and NGOs. Thus, the culture and frequency of engagement developed at the project team level, rather than across SSI. As a result, SSI student experiences varied significantly in terms of: (1) the types of stakeholders with whom they interacted; (2) the level of stakeholder participation in research projects; and (3) the level of empowerment students had to initiate and manage the partnerships. While some students worked closely with project partners designing the research study, collecting data, and analyzing results, other interactions were more cursory, often restricted to brief communication or surveys. For some students, interactions with stakeholders were completely absent. Even with SSI's broad collective experience in and focus on developing and managing partnerships, there was minimal cross-team, formal reflection on the constraints, ethical questions, and lessons learned through these experiences. Despite the lack of formal training opportunities, $67 \%$ of student respondents reported 
they improved at the key skills needed for stakeholder engagement, especially with group facilitation and creative problem solving.

Although SSI leadership and faculty gave significant thought to stakeholder engagement and numerous stakeholder meetings were held during the NSF proposal-writing phase of SSI, many specific research teams formed after funding was received. Therefore some teams did not go through a process of co-identifying their research questions with stakeholders (Lang et al., 2012). This timing mismatch meant that doctoral students did not have the opportunity to experience and learn about this aspect of partnerships, and, at its worst, risked producing research that was not adequately calibrated to the needs of stakeholders. The timeline for making progress on grants as required by grantors is often short and potentially forces teams to develop research questions before adequately engaging stakeholders. As indicated by one student, the disconnect between the researchers and stakeholders at critical phases of the research process (Israel et al., 1998; Lang et al., 2012) was not apparent to everyone at the beginning of our programs:

I didn't realize that the already established project teams were not necessarily planned with community partners. I have found this to be a struggle because it feels like we're playing catch-up, without a lot of flexibility.

We also found that faculty expertise in conducting stakeholder research varied, with some having extensive experience and others having none at all. There was considerable variation in the amount of focus placed on engaging (and teaching about) stakeholder partnerships. In several cases, SSI students brought prior professional stakeholder-partnership experience to augment the team's ability to cultivate these partnerships. 
Our experiences indicate that teams should engage stakeholders early in the process, especially during proposal formation, to help ensure alignment of research questions with stakeholder and researcher needs. In terms of student training, we argue that SS education should emphasize formal training in both the theoretical and practical aspects of research partnerships in order to obtain interpersonal, normative, and strategic competencies (Wiek et al, 2011) that will help students navigate boundaries inherent to university-stakeholder partnerships. One solution would be to require a course that combines theories of partnerships with a guided, experientially based stakeholder partnership practicum that encourages students to reflect, discuss, and learn from their experiences on research teams. A practice-based course would also help students explore the ethics of engagement and justice in sustainability through personal experience with the problem under investigation. Additionally, each team should have at least one member focused on partnership development and facilitation. This person would lead the team's partnerships, develop expertise in this area of research, and would engage other team members in developing these vital SS skills.

\section{Boundary 4: Place-based and generalizable research}

Maine is the most rural state in the United States (USCB, 2010) and consequently SSI's place-based SS focused on problems in rural and urbanizing areas. SSI was uniquely positioned to address a suite of sustainability issues focused on rural, natural resource-based economies compared with other SS programs, which tend to focus on urban areas. The rural nature of Maine along with the New England tradition of home-rule in policy arenas make the local level of stakeholder engagement that much more important. By emphasizing the creation of solutions to local challenges, SSI provided excellent training 
at this scale through SSI-wide informal discussions and on-the-ground stakeholder-based research. While SSI's emphasis on place-based research had many advantages, some respondents questioned if this focus adequately prepared them as scientists to develop generalizable theories that advanced SS as a field.

The need for science to generalize case-study specific knowledge to broad problems epitomizes the difficulty of adequately addressing scale in research projects. Kates et al. (2001) note, "The regional character of much of what SS is trying to explain means that relevant research will have to integrate the effects of key processes across the full range of scales, from local to global" (Kates et al., 2001). The drive to move across scales also comes from major funding organizations, such as NSF, who seek to apply insights to other contexts for the sake of scientific knowledge production and fiscal efficiency. Therefore, adequate training in extrapolating and generalizing research from place-based context to the broader scientific realm is vital for the training of doctoral students, as described by the systemsthinking competence (Wiek et al. 2011).

The process of developing dissertation research questions based on stakeholder-based research enabled many SSI students to walk the line between working with stakeholders on applied questions and contributing to the broader, generalized scientific debate. In the relatively short window of opportunity that doctoral students have, it is difficult to both focus on place-based problems and to develop generalizable SS theories. SSI, with its portfolio model, provided a unique opportunity to study multiple manifestations of sustainability challenges. Though students were immersed in project-based challenges, students lacked formal opportunities to engage in discussions about sustainability challenges across the diverse range of projects. Cross-fertilization and group-problem solving could 
have enhanced student training. We suggest students should be involved in informal and formal discussions that synthesize common challenges and themes across multiple SS projects, which would further their training in identifying cross-cutting sustainability theories, solidify their systems-thinking competency, and strengthen their ability to manage and discuss the boundary between conducting place-based, solutions-oriented SS, while also contributing generalizable knowledge to the field

\section{CONCLUSIONS}

We believe a commitment to improving graduate education in SS is a critical component of crossing the boundary from an emergent field to an established one that has the capacity to address wicked problems. Graduate education should help students master core competencies in theory and practice by providing a methodological foundation from which to conduct research, while also cultivating a universal language that allows researchers and stakeholders to take lessons from the laboratory to the real world. Such common ground is especially important for new generations of sustainability scientists, who may call a wide range of departments and institutions home.

Based on our collective experiences and analysis, we recommend that the SS community utilize key SS competencies (Wiek et. al, 2011 and In Press) and the boundary spanning literature to inform and guide future SS graduate education at universities. By attending to the boundaries discussed in this article - boundaries among disciplines, students and their advisors, academic researchers and stakeholder partners, and place-based and generalizable research - universities establishing such programs can build on the SS competencies identified by Wiek et al. (2011 and In Press). A boundary spanning framework will help programs deliberately and rigorously identify program goals, evaluate 
institutional abilities to deliver the program, and design the necessary components of their SS research and education programs. We believe a framework should foster a culture of mutual learning across three domains: student experience, faculty capacity, and institutional support. It is essential that this be a deliberate effort; simply adapting traditional models of disciplinary graduate education may leave future sustainability scientists ill-equipped to produce new, relevant knowledge and develop significant solutions.

As former graduate students who successfully completed our programs, we offer the following recommendations for institutions interested in training future sustainability scientists:

- Develop a required core curriculum to ground graduate students in the theory and methodologies of SS and to develop core SS competencies. This can be accomplishedby drawing from existing course offerings and designing new, SS-specific courses;

- If graduate students have a home department outside of the SS training program, clearly articulate the dual expectations placed on the students by the program and their home departments for both specialization and breadth;

- Assemble faculty members who have the expertise necessary to mentor advisees in SS, or provide necessary training for faculty who lack such expertise, and re-articulate the expectations for mutual learning throughout graduate training;

- Ensure formal and informal, and theoretical and experiential educational opportunities are part of the students' training;

- Determine and communicate the expected role of the graduate student in the stakeholder engagement process, and provide the necessary training to fulfill that role; and 
- Provide opportunities for, and engage students in, cross-team and program-wide dialogues to share knowledge, develop cross-cutting research questions and knowledge synthesis for theory development and testing.

We believe addressing these components of training programs in a common framework will better prepare the next generation of sustainability scientists to navigate the many boundaries that exist among individuals, disciplines, and institutions when tackling wicked problems. Furthermore, a program that has critically considered these issues during the program development phase will have greater transparency and will offer clear expectations for all participants. Administrators and faculty will benefit by having strong students who are able to make meaningful contributions to the program. Stakeholders will benefit by having strong relationships with scientists that will yield salient, credible, and relevant information to solve problems (Cash et al., 2003). Most importantly for our discussion, graduate students will benefit by gaining a comprehensive SS education, which they can apply throughout their careers.

SS, with its focus on integrating multiple disciplinary perspectives to develop solutions for on-theground problems, provides educational challenges not experienced in traditional disciplinary doctoral programs. However, as graduate students navigate their formal training programs and begin to develop their own research programs, regardless of their disciplinary lens or professional sector, a rigorous grounding in the theory and methods of this field will result in highly skilled, reflexive scientists capable of producing valuable research outcomes. 


\section{REFERENCES}

Allen, J. H., Beaudoin, F., Lloyd-Pool, E., \& Sherman, J. (2014). Pathways to Sustainability Careers: Building Capacity To Solve Complex Problems. Sustainability: The Journal of Record, 7(1), 4753.

Armstrong, L, Loomis, C, Mairena-Torres, E. (2012), "Is participatory research compatible with graduate research? Reflections from three stakeholders", Global Journal of Community Psychology Practice, Vol. 3, pp. 1-10.

Bäckstrand, K. (2003), "Civic science for sustainability: Reframing the role of experts, policy-makers and citizens in environmental governance", Global Environmental Politics, Vol. 3, pp. 24-42.

Borrego, M., Newswander, LK. (2010), "Definitions of interdisciplinary research: Toward graduatelevel interdisciplinary learning outcomes", The Review of Higher Education, Vol. 34, pp. 61-84.

Brundiers, K., \& Wiek, A. (2013). Do we teach what we preach? An international comparison of problem-and project-based learning courses in sustainability. Sustainability, 5(4), 1725-1746.

Bruntland Commssion. (1987), "Our Common Future”, World Commission on Environment and Development, Brussels.

Cash, DW, Clark, WC, Alcock, F, Dickson, NM, Eckley, N, Guston, DH, Jäger, J, Mitchell, RB. (2003), "Knowledge systems for sustainable development", in Proceedings of the National Academy of Sciences Vol. 100, pp. 8086-8091.

Clark, WC, Dickson, NM. (2003), "Sustainability science: the emerging research program", in Proceedings of the National Academy of Sciences of the United States of America, Vol. 100, pp. 8059-61.

Clark, WC. (2007), "Sustainability science: a room of its own", in Proceedings of the National Academy of Sciences of the United States of America, Vol. 104, pp. 1737-8. 
Clark, W. C., Tomich, T. P., van Noordwijk, M., Guston, D., Catacutan, D., Dickson, N. M., McNie, E. (2011), "Boundary work for sustainable development: Natural resource management at the Consultative Group on International Agricultural Research (CGIAR)", in Proceedings of the National Academy of Sciences of the United States of America.

Creswell, JW. (2003), Qualitative, quantitative, and mixed methods approaches. $2^{\text {nd }}$ ed. Sage.

Evans, J, Randalls, S. (2008), “Geography and paratactical interdisciplinarity: Views from the ESRCNERC PhD studentship programme", Geoforum,, Vol. 39, pp. 581-592.

Gardner, SK, Jansujwicz, J, Hutchins, K, Cline, B, Levesque, V. (2012), “Interdisciplinary doctoral student socialization”, International Journal of Doctoral Studies, Vol. 7, pp. 377-394.

Gieryn, TF. (1983), "Boundary-work and the demarcation of science from non-science: Strains and interests in professional ideologies of scientists", American Sociological Review, Vol. 48, pp. 781795.

Graybill, JK, Dooling, S, Shandas, V, Withey, J, Greve, A, Simon, GL. (2006), “A rough guide to interdisciplinarity: Graduate student perspectives”, BioScience, Vol. 56, pp. 757-763.

De Haan, G. (2006) The BLK '21' programme in Germany: a 'Gestaltungskompetenz' - based model for Education for Sustainable Development. Environmental Education Research, 12(1)

Hart, D. D., K. P. Bell, L. A. Lindenfeld, S. Jain, T. R. Johnson, D. Ranco, and B. McGill. (2015). Strengthening the role of universities in addressing sustainability challenges: the Mitchell Center for Sustainability Solutions as an institutional experiment. Ecology and Society 20(2), 4. http://dx.doi.org/10.5751/ES-07283-200204

Holley, K. (2009), "The challenge of an interdisciplinary curriculum: a cultural analysis of a doctoraldegree program in neuroscience", Higher Education, Vol. 58, pp. 241-255. 
Israel BA., Schulz AJ., Parker EA. and Becker AB. (1998), Review of community-based research: assessing partnership approaches to improve public health. Annual Review of Public Health, 19(1):173-202. doi: 10.1146/annurev.publhealth.19.1.173.

Jasanoff, SS. (1987), “Contested boundaries in policy-relevant science”, Social Studies of Science, Vol. 17, pp. 195-230.

Kajikawa, Y. (2008), "Research core and framework of sustainability science”, Sustainability Science, Vol. 3, pp. 215-239.

Kates, RW. (2011), "What kind of a science is sustainability science?" in Proceedings of the National Academy of Sciences of the United States of America, Vol. 108, pp.19449-50.

Kates, RW, Clark, WC, Corell, R, Hall, JM, Jaeger, CC, Lowe, I, McCarthy, JJ, Schellnhuber, HJ, Bolin, B, Dickson, NM, Faucheux, S, Gallopin, GC, Grübler, A, Huntley, B, Jäger, J., Jodah, NS, Kasperson, RE, Mabogunje, A, Matson, P, Mooney, H, Moore, B, O’Riordan, T, Svedin, U. (2001), “Sustainability science”, Science, Vol. 292, pp. 641-642.

Kajikawa, Y., Tacoa, F., \& Yamaguchi, K. (2014). Sustainability science: the changing landscape of sustainability research. Sustainability Science, Vol. 9 No.4,. 431-438.

Kueffer, C., Underwood, E., Hirsch Hadorn, G., Holderegger, R., Lehning, M., Pohl, C., Schirmer, M., Schwarzenbach, R., Stauffacher, M., Wuelser, G., Edwards, P. (2012), “Enabling Effective Problem-oriented Research for Sustainable Development”, Ecology and Society, Vol. 17 No. 4.

Lang, DJ, Wiek, A, Bergmann, M, Stauffacher, M, Martens, P, Moll, P,... and Thomas, CJ (2012) Transdisciplinary research in sustainability science: practice, principles, and challenges. Sustainability Science, Vol. 7 No. 1, 25-43. doi: 10.1007/s11625-011-0149-x 
McGreavy, B., Lindenfeld, L., Bieluch, K., Silka, L., Leahy, J., \& Zoellick, B. (2015) Communication and sustainability science teams as complex systems. Ecology and Society. 20(1), 2. http://dx.doi.org/10.5751/ES-06644-200102.

McGreavy, B., Hutchins, K., Smith, H., Lindenfeld, L., Silka, L. (2013) Addressing the complexities of boundary work in sustainability science through communication. Sustainability, 5(10), 4195-4221; doi:10.3390/su5104195.

Miller, TR, Baird, TD, Littlefield, CM, Kofinas, G, Chapin, FS, Redman, CL. (2008), "Epistemological pluralism: Reorganizing interdisciplinary research”, Ecology and Society, Vol. 13 No. 2.

Miller, T.R. (2013). Constructing sustainability science: emerging perspectives and research trajectories. Sustainability Science, Vol. 8, 279-293.doi: 10.1007/s11625-012-0180-6.

Moslemi, JM, Capps, KA, Johnson, MS, Maul, J, Intyre, PB, MC, Melvin, AM, Vadas, TM, Vallano, DM, Watkins, JM, Weiss, M. (2009), “Training tomorrow’s environmental problem solvers: An integrative approach to graduate education", BioScience, Vol. 59, pp. 514-521.

National Science Foundation. (2012), "Doctorate recipients from U.S. universities", available at: http://www.nsf.gov/statistics/sed/2012/data_table.cfm (accessed 2 January 2014).

Palmer, M. (2012). Socioenvironmental Sustainability and Actionable Science. BioScience, 62(1), 5-6. doi:10.1525/bio.2012.62.1.2

Polk, M (2014) Achieving the promise of transdisciplinarity: a critical exploration of the relationship between transdisciplinary research and societal problem solving. Sustainability Science 9:1-13. doi: $10.1007 / \mathrm{s} 11625-014-0247-7$

Reed, MS, Fraser, EDG, Dougill, AJ. (2006), “An adaptive learning process for developing and applying sustainability indicators with local communities", Ecological Economics, Vol. 59, pp. 406-418. 
Reich, SM, Reich, JA. (2006), "Cultural competence in interdisciplinary collaborations: a method for respecting diversity in research partnerships", American Journal of Community Psychology, Vol. 38, pp. 51-62.

Rittel, HWJ, Webber, MM. (1973), "Dilemmas in a general theory of planning", Policy Sciences, Vol. 4, pp. $155-169$.

Schmidt, AH, Robbins, AST, Combs, JK, Freeburg, A, Jesperson, RG, Rogers, HS, Sheldon, KS, Wheat, E. (2012), "A new model for training graduate students to conduct interdisciplinary, interorganizational, and international research", BioScience, Vol. 62, pp. 296-304.

Schoolman, ED, Guest, JS, Bush, KF, Bell, AR. (2012), "How interdisciplinary is sustainability research? Analyzing the structure of an emerging scientific field", Sustainability Science, Vol. 7, pp. 67-80.

Silka, L. (1999), "Paradoxes of Partnership: Reflections on University-Community Partnerships", Kleniewski, N, Rabrenovic, G., Research in Politics and Society: Community Politics and Policies, JAI Press, pp. 335-359.

Tress, B, Tress, G, Fry, G. (2009), "Integrative research on environmental and landscape change: PhD students' motivations and challenges", Journal of Environmental Management, Vol. 90, pp. 29219.

[USCB] US Census Bureau. (2010) “Urban and Rural Classification”, available at: http://www.census.gov/geo/reference/ua/urban-rural-2010.html (accessed 9 December 2013). van Kerkhoff, L, and Lebel, L. (2006), "Linking knowledge and action for sustainable development”, Annual Review of Environment and Resources, Vol. 31, pp. 445-477.

van Kerkhoff L (2014) Developing integrative research for sustainability science through a complexity principles-based approach. Sustainability Science, 9(2):143-155. doi: 10.1007/s11625-013-0203-y 
Wagner, HH, Murphy, MA, Holderegger, R, and Waits, L. (2012), "Developing an interdisciplinary, distributed graduate course for twenty-first century scientists", BioScience, Vol. 62, pp. 182-188.

Weber, EP, Khademian, AM. (2008), "Wicked problems, knowledge challenges, and collaborative capacity builders in network settings", Public Administration Review, Vol. 68, pp. 334-349.

Weidman, JC, Twale, D J, Stein, E L. (2001), "Socialization of graduate and professional students in higher education: A perilous passage?” ASHE-ERIC Higher Education Report, Vol. 28 No. 3.

Weerts, DJ, Sandmann, LR. (2010), “Community engagement and boundary spanning roles at public research universities", Journal of Higher Education, Vol. 81, pp. 632-657.

Whitmer, A., Ogden, L., Lawton, J., Sturner, P., Groffman, P. M., Schneider, L, Hart, D., Halpern, B., Schlesinger, W., Raciti, S., Bettez, N., Ortega, S., Rustad, L., Pickett, S., Killilea, M. (2010), “The engaged university: providing a platform for research that transforms society", Frontiers in Ecology and the Environment, Vol. 8, pp. 314-321.

Wiek, A., Bernstein, M. J., Foley, R., Cohen, M., Forrest, N., Kuzdas, C., ... Keeler, L. (In Press). Operationalising Competencies in Higher Education for Sustainable Development. In M. Barth, G. Michelsen, M. Rieckmann, \& I. Thomas (Eds.), Handbook of Higher Education. Routledge. Wiek, A., Withycombe, L., \& Redman, C. L. (2011). Key competencies in sustainability: a reference framework for academic program development.Sustainability Science, 6(2), 203-218. 